\title{
Eicosapentaenoic acid actions on adiposity and insulin resistance in control and high-fat-fed rats: role of apoptosis, adiponectin and tumour necrosis factor- $\alpha$
}

\author{
Patricia Pérez-Matute, Nerea Pérez-Echarri, J. Alfredo Martínez, Amelia Marti \\ and María J. Moreno-Aliaga* \\ Department of Physiology and Nutrition, University of Navarra, 31008 Pamplona, Spain
}

(Received 11 April 2006 - Revised 6 July 2006 - Accepted 14 July 2006)

\begin{abstract}
n-3 PUFA have shown potential anti-obesity and insulin-sensitising properties. However, the mechanisms involved are not clearly established. The aim of the present study was to assess the effects of EPA administration, one of the $n-3$ PUFA, on body-weight gain and adiposity in rats fed on a standard or a high-fat (cafeteria) diet. The actions on white adipose tissue lipolysis, apoptosis and on several genes related to obesity and insulin resistance were also studied. Control and cafeteria-induced overweight male Wistar rats were assigned into two subgroups, one of them daily received EPA ethyl ester $(1 \mathrm{~g} / \mathrm{kg})$ for 5 weeks by oral administration. The high-fat diet induced a very significant increase in both body weight and fat mass. Rats fed with the cafeteria diet and orally treated with EPA showed a marginally lower body-weight gain $(P=0 \cdot 09)$, a decrease in food intake $(P<0 \cdot 01)$ and an increase in leptin production $(P<0 \cdot 05)$. EPA administration reduced retroperitoneal adipose tissue weight $(P<0 \cdot 05)$ which could be secondary to the inhibition of the adipogenic transcription factor PPAR $\gamma$ gene expression $(P<0.001)$, and also to the increase in apoptosis $(P<0.05)$ found in rats fed with a control diet. TNF $\alpha$ gene expression was significantly increased $(P<0.05)$ by the cafeteria diet, while EPA treatment was able to prevent $(P<0.01)$ the rise in this inflammatory cytokine. Adiposity-corrected adiponectin plasma levels were increased by EPA. These actions on both TNF $\alpha$ and adiponectin could explain the beneficial effects of EPA on insulin resistance induced by the cafeteria diet.
\end{abstract}

Eicosapentaenoic acid: High-fat diets: White adipose tissue: Insulin resistance

n-3 PUFA present in fish oil are known to have numerous beneficial effects on health (Connor, 2000; Ruxton, 2004), suggesting important anti-adipogenic properties of EPAenriched diets (Raclot et al. 1997). However, other trials have not observed any effects on body-weight gain and visc?eral fat after EPA treatment (Kusunoki et al. 2003). In this context, previous studies by our group in primary cultured rat adipocytes (Perez-Matute et al. 2005) and by others in 3T3-L1 cells (Murata et al. 2000) demonstrated that EPA was able to stimulate leptin gene expression and protein secretion. These data suggest potential anti-obesity effects of EPA in vivo since leptin is a hormone primarily secreted by white adipose tissue (WAT) involved in the regulation of body weight and body fat stores via its central actions on food intake and energy expenditure (Marti \& Martinez, 1999).

In order to better elucidate the potential EPA anti-obesity actions, we analysed the effects of its administration in rats fed on a standard diet or a high-fat (cafeteria) diet (MorenoAliaga et al. 2002; Perez-Echarri et al. 2005). Our cafeteriafed rats constitute a useful model for obesity studies because a high fat intake is a key factor in the development of obesity (Lopez et al. 2003).

The mechanisms (alterations of adipogenesis, lipolysis, apoptosis) involved in these potential anti-obesity actions of
EPA remain unclear. Some studies have suggested that an inhibition of PPAR $\gamma$ gene expression, a transcription factor with a key role as master regulator of adipogenesis, could be involved in the potential anti-obesity actions of EPA (Reseland et al. 2001). However, controversial data are described (Chambrier et al. 2002). Furthermore, contradictory results regarding the lipolytic action of $n-3$ fatty acids have also been shown (Rustan et al. 1993; Raclot et al. 1997). On the other hand, several authors suggested that EPA limits fat cell trophic growth without modifying the cell number (Parrish et al. 1990). However, others have observed a reduction in cellularity of mice epididymal adipose tissue after treatment with n-3 PUFA-enriched diets (Ruzickova et al. 2004), suggesting a possible apoptotic effect of EPA, although this fact has not been yet addressed. Therefore, the aim of the present study was to assess for the first time the direct potential apoptotic effects of EPA in WAT. In addition, we also tested EPA effects on WAT lipolysis ex vivo and on adipogenic PPAR $\gamma$ gene expression.

EPA treatment has also been suggested to improve insulin resistance in several models of obesity and diabetes in rodents (Mori et al. 1997, 1999; Nobukata et al. 2000). Obesity has been associated with an inflammatory state which has been proposed to be the link with several obesity-associated

Abbreviations: HOMA, homeostasis model assessment; OEPA, overweight EPA; WAT, white adipose tissue.

* Corresponding author: Dr María J. Moreno-Aliaga, fax +34 948425649, email mjmoreno@unav.es 
disorders such as insulin resistance, CVD and metabolic syndrome (Dandona et al. 2004; Moreno-Aliaga et al. 2005). This inflammatory state associated with obesity appears to be predominantly triggered and to reside in adipose tissue (Wellen \& Hotamisligil, 2003). The expression and release of inflammation-related adipokines generally rises as adipose tissue expands, except for adiponectin, which has an antiinflammatory action (Trayhurn \& Wood, 2005). Thus, plasma adiponectin concentrations are decreased in obesity and are positively associated with whole-body insulin sensitivity (Stefan et al. 2002). EPA and DHA are well known to have anti-inflammatory properties (Mori \& Beilin, 2004), and the ability of fish oil to alter cytokine production from several cell types and reduce pro-inflammatory cytokines has been described (Calder, 2001; Browning, 2003). However, to our knowledge there are no data available regarding the potential anti-inflammatory actions of $n-3$ fatty acids in adipose tissue. In order to address this question, in the present study we analysed the effects of EPA supplementation on the proinflammatory cytokine $\mathrm{TNF} \alpha$ gene expression in WAT. In addition, adiponectin gene expression and protein production were also studied.

In summary, the present trial provides novel insights into the mechanisms involved in the anti-adipogenic and insulinsensitising actions of EPA on WAT, especially regarding its effects on apoptosis, TNF $\alpha$ and adiponectin production.

\section{Material and methods}

\section{Animals and treatment}

Twenty-nine male Wistar rats weighing about $180 \mathrm{~g}$ (6 weeks old) were obtained from the Centre of Applied Pharmacology (CIFA, Pamplona, Spain). Animals were housed (two or three per cage) in polycarbonate cages in temperature-controlled rooms $\left(22 \pm 2^{\circ} \mathrm{C}\right)$ with a $12 \mathrm{~h}$ light-dark cycle, fed a pelleted chow diet (Rodent Toxicology Diet; B\&K Universal, Aldbrough, Hull, UK) and given deionised water ad libitum for an adaptation period of $4 \mathrm{~d}$. Rats were then assigned to two dietary groups for 5 weeks. The control group ( $n$ 15) was fed a standard pelleted chow laboratory diet containing $18 \%$ of energy as protein, $76 \%$ of energy as carbohydrate and $6 \%$ of energy as lipid by dry weight. The overweight group ( $n$ 14) was fed on a fat-rich hyperenergetic 'cafeteria' diet composed of paté, chips, chocolate, bacon, biscuits and pelleted diet in a proportion of $2: 1: 1: 1: 1: 1$ as previously described (Moreno-Aliaga et al. 2002; Perez-Echarri et al. 2005). The composition was $9 \%$ of energy as protein, $29 \%$ as carbohydrate and $62 \%$ as lipid by dry weight. The fatty acid composition of both diets (control and cafeteria) is showed in Table 1. Both dietary groups were divided into two new subgroups. One subgroup from each dietary group received by oral administration EPA ethyl ester $(1 \mathrm{~g} / \mathrm{kg}$ per $\mathrm{d})$ daily for 5 weeks (control EPA and overweight EPA (CEPA and OEPA) groups). The other subgroups of rats (control and overweight) received by oral administration the same volume of water as previously shown in other studies (Mori et al. 1997; Kusunoki et al. 2003). These groups of rats without treatment with any other type of fatty acid (such as saturated fatty acids with equal chain length as EPA or oleic acid) are more likely to be considered as control groups in
Table 1. Fatty acid composition (\%) of control and cafeteria diets

\begin{tabular}{|c|c|c|}
\hline Fatty acid & Control diet & Cafeteria diet \\
\hline $12: 0$ (Lauric) & 0.00 & 0.00 \\
\hline $14: 0$ (Myristic) & 0.76 & 0.70 \\
\hline $16: 0$ (Palmitic) & $14 \cdot 42$ & $29 \cdot 82$ \\
\hline 16: 1n-7 (Palmitoleic) & 0.76 & $1 \cdot 75$ \\
\hline $18: 0$ (Stearic) & $3 \cdot 19$ & $13 \cdot 45$ \\
\hline 18: 1n-9 (Oleic) & 22.91 & $40 \cdot 80$ \\
\hline 18:2n-6 (Linoleic) & $51 \cdot 12$ & $12 \cdot 48$ \\
\hline 18: 3n-3 (Linolenic) & 5.92 & 0.22 \\
\hline $20: 0$ (Arachidic) & 0.00 & 0.65 \\
\hline $20: 4 n-6$ (Arachidonic) & 0.00 & 0.11 \\
\hline $20: 5 n-3$ (Eicosapentaenoic) & 0.00 & 0.00 \\
\hline $22: 1 n-9$ (Erucic) & 0.83 & 0.03 \\
\hline $22: 6 n-3$ (Docosahexaenoic) & 0.09 & 0.00 \\
\hline
\end{tabular}

our study design. This is because it has been demonstrated that supplementation with some other fatty acids is able to modify adiposity and the circulating levels of biochemical and hormonal markers planned to be determined in the present study (Mori et al. 1997).

Body weight and food intake were daily recorded. At the end of the experimental period and after an overnight fast, rats were killed by decapitation and blood and tissue samples were collected and kept at $-80^{\circ} \mathrm{C}$ for subsequent analysis. All procedures were conducted under protocols approved by the University Ethics Committee for the use of laboratory animals.

\section{Biochemical measurements}

Serum glucose was measured using an autoanalyser (Cobas Roche Diagnostic, Basel, Switzerland). Plasma insulin and leptin were assayed by RIA (Linco Research, St Charles, MO, USA). Adiponectin concentrations in serum were determined by a Mouse/Rat Adiponectin ELISA kit (B-Bridge International, Inc., Sunnyvale, CA, USA).

\section{Adipocyte isolation and ex vivo lipolysis}

Adipocytes were isolated from retroperitoneal fat pads of male Wistar rats. The fat pads were minced into pieces in KrebsRinger HEPES buffer ( $\mathrm{pH} 7.4$; containing $5 \mathrm{mM}$-D-glucose, $2 \%$ bovine serum albumin, $135 \mathrm{mM}-\mathrm{NaCl}, 2.2 \mathrm{mM}-$ $\mathrm{CaCl}_{2} .2 \mathrm{H}_{2} \mathrm{O}, \quad 1.25 \mathrm{~mm}-\mathrm{MgSO}_{4} .7 \mathrm{H}_{2} \mathrm{O}, \quad 0.45 \mathrm{~mm}-\mathrm{KH}_{2} \mathrm{PO}_{4}$,

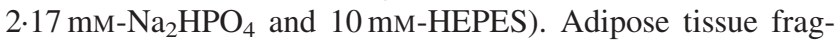
ments were digested in the same buffer with type I collagenase $(1.25 \mathrm{mg} / \mathrm{ml}$ per $0.5 \mathrm{~g}$ tissue; Worthington, Lakewood, NJ, USA) at $37^{\circ} \mathrm{C}$ with gentle shaking at sixty cycles/min for $30 \mathrm{~min}$. The resulting cell suspension was diluted in HEPESphosphate buffer and the isolated adipocytes were then separated from the undigested tissue by filtration through a $400 \mu \mathrm{m}$ nylon mesh and washed three times. Ex vivo lipolysis was performed in isolated adipocytes according to Campion \& Martínez (2004). Results were expressed as $\mu$ mol glycerol released per $100 \mathrm{mg}$ total lipids after $90 \mathrm{~min}$ of incubation in Krebs-Ringer buffer.

\section{Detection of white adipose tissue apoptosis}

Apoptotic cell death was measured by using the Cell Death Detection ELISA ${ }^{\text {PLUS }}$ kit (Boehringer Mannheim 
Biochemicals, Indianapolis, IN, USA). This is a photometric enzyme-immunoassay for quantitative in vitro determination of cytoplasmic histone-associated DNA fragments, which are generated during apoptosis, using monoclonal antibodies directed against DNA and histones, respectively. All experimental procedures were carried out on ice. The assay was performed according to the manufacturer's instructions, reading absorbance at $405 \mathrm{~nm}$ and subtracting absorbance at $490 \mathrm{~nm}$ for each well $\left(\mathrm{A}_{405}-\mathrm{A}_{490}\right)$. Data represent average values from double absorbance measurements of each sample and were calculated subtracting the background value of the immunoassay from each value (Margareto et al. 2000).

\section{Gene expression levels in white adipose tissue}

Epididymal adipose tissue mRNA expression levels were determined by Northern blotting as described by PérezMatute et al. (2003). The leptin cDNA probe was a $388 \mathrm{bp}$ fragment whereas adiponectin cDNA probe was a $497 \mathrm{bp}$ fragment. They were kindly provided by Dr Charles Mobbs (Mount Sinai School of Medicine, New York), which is gratefully acknowledged. The PPAR $\gamma 2$ cDNA probe (Genbank accession number Y12882) was a $570 \mathrm{bp}$ fragment of rat cDNA, and the primers used were $5^{\prime}$-TCTGATTATGGGTGAAACTC-3' (sense 43-62) and 5'-TTTCTACTCTTTTTGTGGATC-3' (antisense 592-612). A 320 bp TNF $\alpha$ DNA fragment was prepared by the PCR with primers corresponding to the nucleotides 923-942 (5'-CCCCATTACTCTGACCCCTT- $\left.3^{\prime}\right)$ and 1223-1242 (5'-AGGCCTGAGACATCTTCAGC- $3^{\prime}$ ) of rat TNF $\alpha$ cDNA (Genbank accession number AF329987) (Kawaguchi et al. 2003). The 18S ribosomal probe was obtained from Ambion (Austin, TX, USA). mRNA expression levels were normalised with respect to this $18 \mathrm{~S}$ ribosomal signal. Signals were quantified using a Sharp JX-325 densitometric scanner (Sharp Electric, Tokyo, Japan) and the analysis was carried out with the software ImageMaster $^{\mathrm{TM}}$ (Pharmacia Biotech, Uppsala, Sweden).

\section{Statistical analysis}

Results are given as mean values with their standard errors. Statistical differences and interactions were evaluated with a factorial two-way ANOVA (diet $\times$ EPA treatment). When statistically significant differences resulted at the interaction level, a Student's $t$ test was carried out to compare the effects of each treatment (GraphPad Prism; GraphPad Software Inc., San Diego, CA, USA). Differences were considered as statistically significant at $P<0 \cdot 05$.

\section{Results}

\section{Effects on body-weight gain and food intake}

High-fat-fed rats showed a significant increase in both final body weight $(P<0.001)$ and body-weight gain $(P<0.001)$ at the end of the experimental trial as compared with control animals (Fig. 1). The administration of EPA $(1 \mathrm{~g} / \mathrm{kg})$ did not significantly alter body-weight gain, although a marginal decrease $(P=0.09)$ could be observed after EPA treatment in the group of rats fed with the cafeteria diet (OEPA).

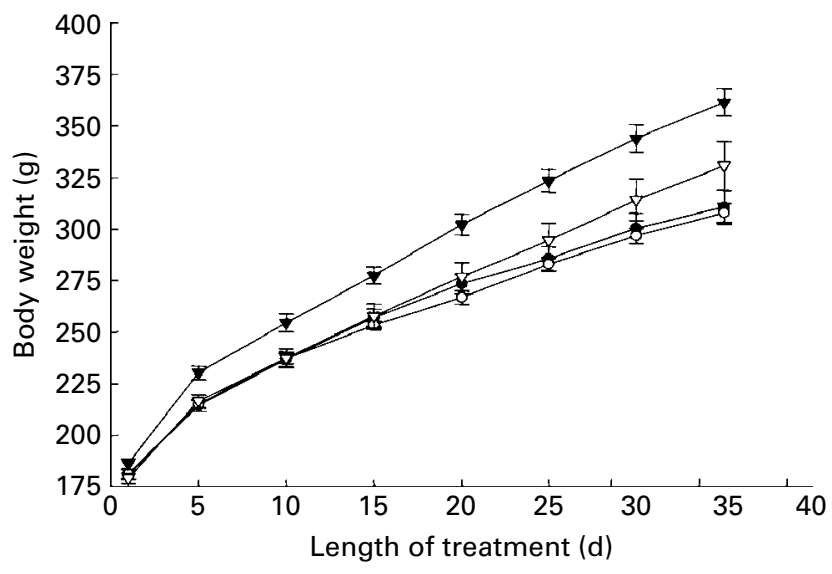

Fig. 1. Effects of EPA ( $35 \mathrm{~d}$ treatment) on the growth curve in rats: control rats $(n 8 ;-\bullet-)$, control rats treated with EPA $(1 \mathrm{~g} / \mathrm{kg} ; n 7 ;-\bigcirc-)$, overweight rats (high-fat-diet; $n 7 ;-\mathbf{v - )}$ ) and overweight rats treated with EPA (1 g/kg; $n 7 ;-\nabla-)$. Body weight was daily recorded. Data are means, with standard errors represented by vertical bars. Statistical analysis was by two-way ANOVA; the effect of diet was significant $(P<0.001)$.

Energy intake was measured in order to find out if the differences showed in body-weight evolution could be related to differences in food intake. Overweight rats (fed with a highfat diet) showed a significant increase in their food intake $(P<0.001)$, which was reduced in part by EPA treatment $(P<0 \cdot 01)$. Feed efficiency, the weight gain:energy consumed ratio, was significantly decreased $(P<0.001)$ in all groups receiving the high-fat diet as compared with the control group. However, EPA treatment did not modify this parameter (Table 2).

\section{Effects on white adipose tissue weights}

Wet weights (g) of WAT from overweight rats were significantly higher than in lean animals $(P<0 \cdot 001)$. Daily administration of EPA produced a significant reduction $(P<0.05)$ in retroperitonal adipose tissue weight. Indeed, EPA treatment showed a tendency (non-significant) to decrease the weight of all the fat pads, but only in the group of animals fed with a standard diet (Table 2).

Regarding brown adipose tissue, animals fed with the cafeteria diet showed an increase in brown fat $(P<0.001)$ as compared with control rats, while the administration of EPA did not modify the size of this fat depot (Table 2).

\section{Effects on plasma biochemical parameters}

Neither the cafeteria diet nor EPA treatment modified glucose plasma levels; however, a slight increase was observed after the consumption of the high-fat diet $(P=0.08)$. EPA treatment induced a significant reduction $(P<0.05)$ in both insulin plasma levels and the homeostasis model assessment (HOMA) index, an index of insulin resistance, suggesting that EPA is able to partially prevent the development of insulin resistance induced in a non-significant manner by the cafeteria diet (Table 3). 
No differences in the relative apoptosis rate were observed in overweight rats as compared with the basal apoptosis of the control rats. EPA treatment induced a marked increase $(P<0.05)$ in the levels of histone-associated DNA oligonucleosomal fragments, a characteristic marker of apoptosis in the group of animals fed with the standard diet but not in the high-fat-fed rats (Fig. 2).

\section{Effects on ex vivo lipolysis}

High-fat-diet feeding caused a significant decrease $(P<0.05)$ in isoproterenol-stimulated lipolytic response in both EPAtreated and untreated rats (Fig. 3). EPA treatment, however, did not affect either basal lipolysis (data not shown) or isoproterenol-induced lipolysis (Fig. 3).

\section{Effects on leptin circulating levels and gene expression}

Regarding leptin circulating levels, a significant interaction $(P<0.01)$ was obtained between diet and EPA treatment. As expected, leptin levels were significantly higher $(P<0.05)$ in the cafeteria-fed group as compared with control animals. EPA treatment significantly decreased leptin circulating levels $(P<0 \cdot 01)$ in the group of animals fed on a standard diet while a significant increase $(P<0.05)$ was observed in overweight rats treated with the fatty acid (Fig. 4 (A)). When leptin serum concentrations were corrected for adiposity (leptin per $\mathrm{g}$ WAT), which was estimated by the sum of all fat depots collected (see Table 2 ), a significant decrease $(P<0 \cdot 05)$ was observed in the group of control animals treated with EPA. On the contrary, EPA caused a significant elevation of leptin production levels $(P<0 \cdot 01)$ in the high-fat-fed rats (Fig. 4 (B)). Similarly, leptin gene expression in epididymal fat showed the same pattern as circulating levels (Fig. 4 (C)).

Effects on adiponectin circulating levels and gene expression

Regarding adiponectin, cafeteria-diet feeding significantly increased adiponectin circulating levels $(P<0.001)$; however, EPA treatment did not affect the circulating levels of this adipokine (Fig. 5 (A)). When adiponectin concentrations were corrected for adiposity (adiponectin per g WAT), a marginally non-significant decrease $(P=0.07)$ was observed in the cafeteria-fed group. Furthermore, EPA treatment induced a significant increase $(P<0.05)$ in adiponectin concentrations per $\mathrm{g}$ WAT (Fig. 5 (B)).

Northern blot analysis revealed three mRNA bands for adiponectin in rats (Hu et al. 1996). In agreement with the observed levels of serum adiponectin, an increase in adiponectin gene expression in WAT was also observed after EPA treatment (Fig. 5 (C)).

Several studies have suggested that there is a strong relationship between low adiponectin levels and insulin resistance (Hotta et al. 2001). In fact, our data showed an inverse relationship between serum adiponectin levels corrected for adiposity and HOMA index $(r-0.43 ; P<0.05)$. 
Table 3. Serum glucose, plasma insulin and homeostasis model assessment (HOMA) index in control and eicosapentaenoic acid-treated lean and overweight rats*

(Mean values with their standard errors)

\begin{tabular}{|c|c|c|c|c|c|c|c|c|c|c|c|}
\hline & \multicolumn{2}{|c|}{$\begin{array}{l}\text { Control } \\
(n 8)\end{array}$} & \multicolumn{2}{|c|}{$\begin{array}{c}\text { CEPA } \\
(n 7)\end{array}$} & \multicolumn{2}{|c|}{$\begin{array}{l}\text { Overweight } \\
\qquad(n 7)\end{array}$} & \multicolumn{2}{|c|}{$\begin{array}{l}\text { OEPA } \\
(n 7)\end{array}$} & \multicolumn{3}{|c|}{$2 \times 2$ ANOVA } \\
\hline & Mean & SE & Mean & SE & Mean & SE & Mean & SE & Diet & EPA & Diet $\times E P A$ \\
\hline Glucose (mg/l) & 948 & 27 & 933 & 37 & 1045 & 35 & 958 & 33 & $P=0.08$ & NS & NS \\
\hline Insulin (рм) & 161.5 & $27 \cdot 0$ & 78.0 & $5 \cdot 3$ & $195 \cdot 8$ & $46 \cdot 6$ & 138.8 & $16 \cdot 4$ & NS & $P<0.05$ & NS \\
\hline HOMAt & 5.4 & 0.9 & 2.5 & 0.08 & $7 \cdot 1$ & 1.6 & 4.8 & 0.5 & NS & $P<0.05$ & NS \\
\hline
\end{tabular}

CEPA, control EPA; OEPA, overweight EPA.

${ }^{*}$ Data were analysed by two-way ANOVA.

†HOMA $=$ insulin $(\mu$ Units $) \times$ glucose $(\mathrm{mmol} / \mathrm{l}) / 22.5$.

Effects on white adipose tissue peroxisome proliferatoractivated receptor- $\gamma$ and tumour necrosis factor- $\alpha$ gene expression

The expression of the adipogenic factor PPAR $y$ was significantly $(P<0.001)$ decreased by EPA treatment in both control and cafeteria-fed animals (Figs. 6 (A) and (B)).

As is observed in Figs. 6 (C) and (D), TNF $\alpha$ gene expression was significantly stimulated $(P<0.05)$ by cafeteria-diet feeding. EPA treatment was able to prevent $(P<0 \cdot 01)$ the rise in the expression of this inflammatory cytokine induced by the high-fat diet.

\section{Discussion}

Animals fed with a high-energy-yielding diet during $35 \mathrm{~d}$ exhibited a significant increase in body-weight gain. EPA treatment, however, was not able to prevent this increase induced by the high-fat diet, although a moderate lower body-weight gain was observed in the group of animals fed with the high-fat diet and orally treated with EPA. These results are in agreement with those from Kusunoki et al. (2003) who did not observe any significant effect of EPA treatment (concentrations from $0 \cdot 3$ to $1 \mathrm{~g} / \mathrm{kg}$ ) on body-weight

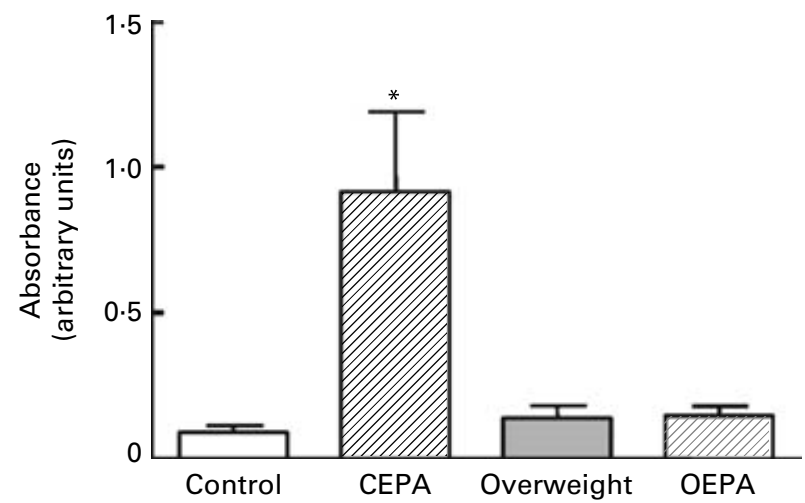

Fig. 2. Effects of EPA on apoptosis in white adipose tissue of control and overweight rats. Data are means for at least seven independent animals per group, with standard errors represented by vertical bars. Statistical analysis was by two-way ANOVA; the diet $\times$ EPA interaction was significant $(P<0.01)$. When an interaction was found, comparisons between groups were analysed by a Student's $t$ test. *Mean value was significantly different from that of the control group $(P<0.05)$. CEPA, control EPA; OEPA, overweight EPA. gain in Otsuka Long-Evans Tokushima Fatty (OLETF) rats. Energy intake was measured in order to find out if the moderate differences showed in body-weight evolution could be related to differences in food intake. As in previous studies, animals fed with the high-fat diet showed an increase in food intake in comparison with the control group, probably because palatability is the predominant force driving the hyperphagia in cafeteria-fed animals (Berraondo et al. 2000; Margareto et al. 2001). Interestingly, EPA treatment was able to decrease food intake, but only in the group of animals fed on the cafeteria diet (OEPA). It is well known that rising concentrations of leptin generate a signal to reduce food intake and increase energy expenditure (Havel, 2004). Taking into account this role of leptin in body-weight regulation, it could be suggested that the EPA-induced increase in leptin production specifically observed in the cafeteria-fed rats could explain the decrease in food intake observed in this group of animals. Peyron-Caso et al. (2002) also described an increase in leptin concentrations in rats fed an n-3 PUFA-enriched diet. In addition, our previous studies in primary cultured rat adipocytes also demonstrated a stimulatory action of EPA on leptin production (Perez-Matute et al. 2005). However, other studies showed an inhibitory action of this fatty acid on leptin (Raclot et al. 1997; Reseland et al. 2001). These conflicting results could be due to the observations that the effects of $n-3$ PUFA on leptin are depen-

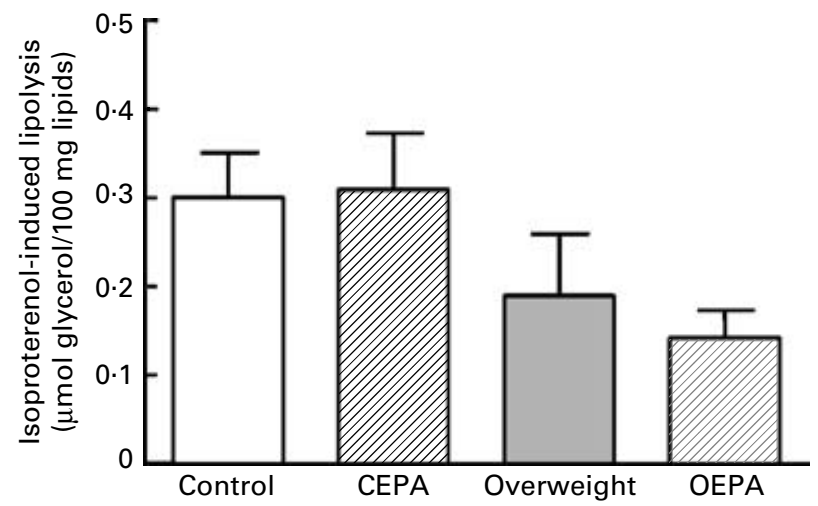

Fig. 3. Effects of EPA on isoproterenol-induced lipolysis in white adipose tissue from control and overweight-cafeteria rats. Data are means for at least four independent animals per group, with standard errors represented by vertical bars. Statistical analysis was by two-way ANOVA; the effect of diet was significant $(P<0 \cdot 05)$. CEPA, control EPA; OEPA, overweight EPA. 

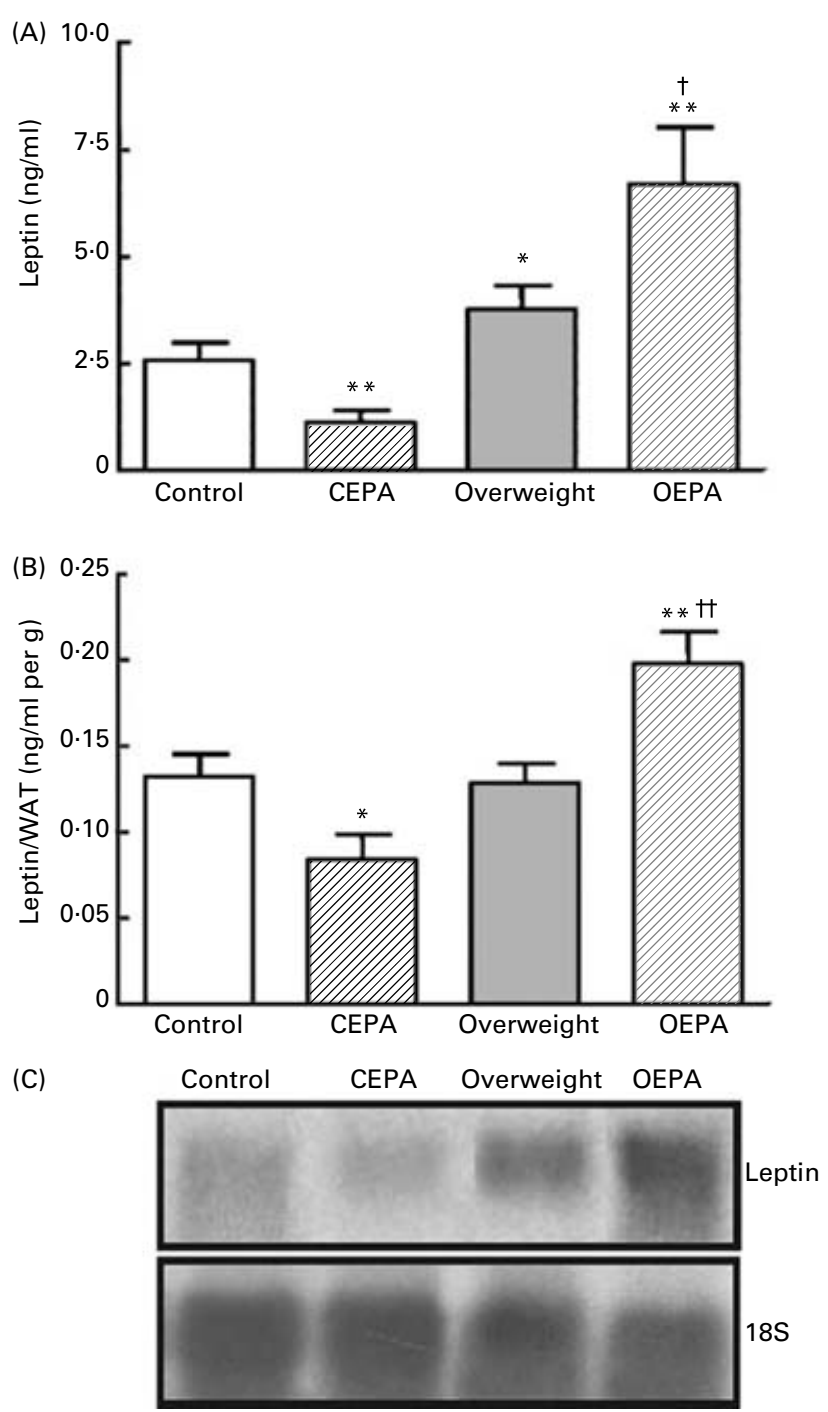

Fig. 4. Effects of EPA on leptin circulating levels (A), leptin concentrations expressed per $\mathrm{g}$ white adipose tissue (WAT) (B) and mRNA expression in epididymal fat $(C)$ in control and overweight-cafeteria rats. The expression level of $18 \mathrm{~S}$ ribosomal RNA was determined and used as an internal control to correct for minor variation in total RNA amount. Densitometric scanning was used to determine the relative amount of leptin mRNA and 18S RNA. Data are means for at least seven independent animals per group ( $n 4$ in Northern blot), with standard errors represented by vertical bars. Statistical analysis was by two-way ANOVA; the diet $\times$ EPA interaction was significant for leptin $(P<0.01)$ and for leptin/WAT $(P<0.001)$. When an interaction was found, comparisons between groups were analysed by Student's $t$ test. Mean value was significantly different from that of the control group: ${ }^{*} P<0.05$, ${ }^{* \star} P<0.01$. Mean value was significantly different from that of the overweight group: $\uparrow P<0.05, \uparrow \dagger P<0.01$. CEPA, control EPA; OEPA, overweight EPA.

dent on a number of factors such as diet composition and energy balance. In this way, the present results showed opposite effects of EPA treatment in control rats in comparison with the overweight group. Other studies have also observed differential actions of some anti-obesity treatments (such as $\beta$-adrenergic agonist) on genes related to energy homeostasis between control and obese animals (Berraondo et al. 2000).

With regard to adiposity, EPA treatment induced a depotspecific reduction in the weight of retroperitoneal fat, as previously observed by Raclot et al. (1997). Furthermore, EPA treatment also induced a moderate reduction in the weight
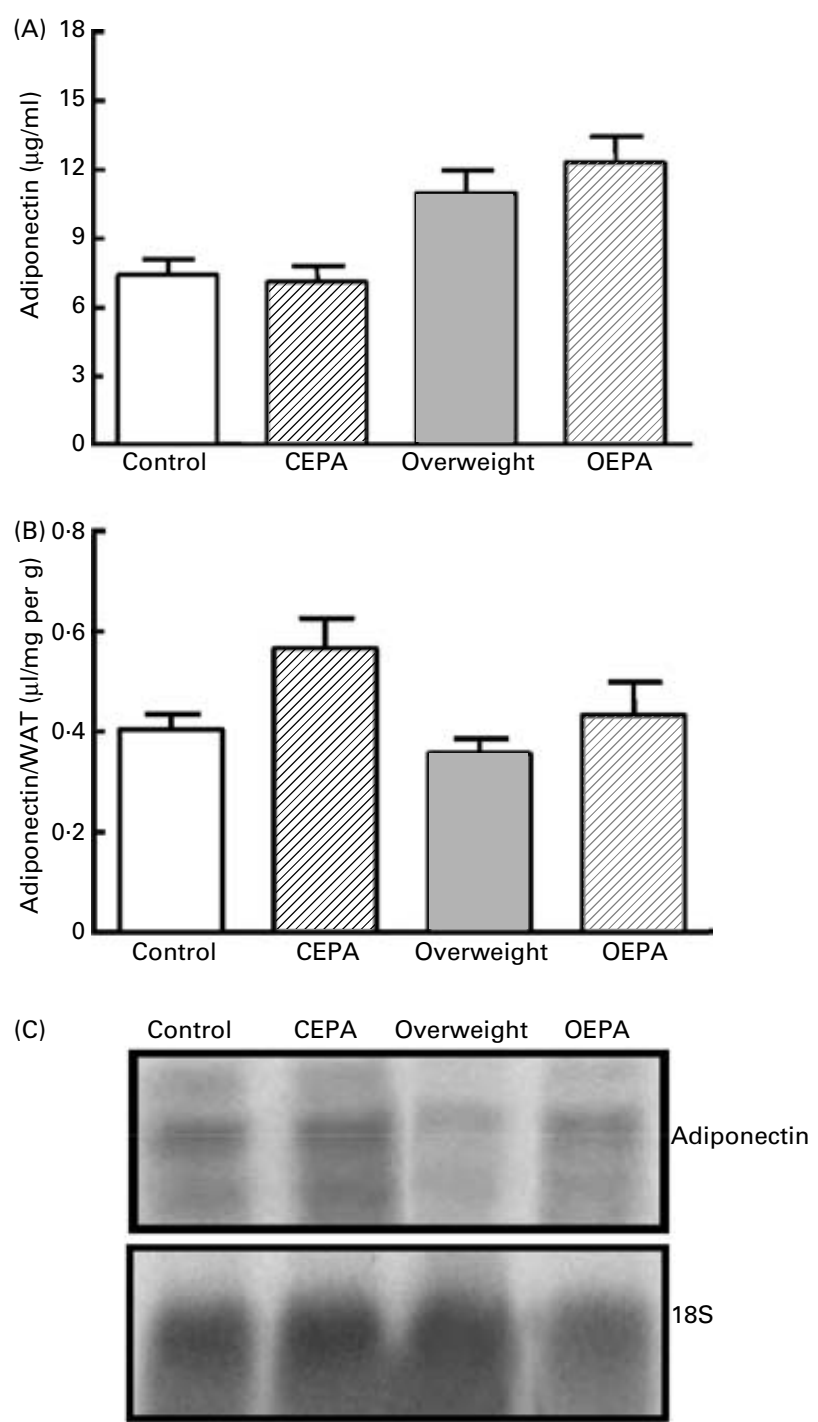

Fig. 5. Effects of EPA on adiponectin circulating levels (A), adiponectin concentrations expressed per $g$ white adipose tissue (WAT) (B) and mRNA expression in epididymal fat $(\mathrm{C})$ in control and overweight-cafeteria rats. The expression level of $18 \mathrm{~S}$ ribosomal RNA was determined and used as an internal control to correct for minor variation in total RNA amount. Densitometric scanning was used to determine the relative amount of adiponectin mRNA and 18S RNA. Data are means for at least seven independent animals per group ( $n 4$ in Northern blot), with standard errors represented by vertical bars. Statistical analysis was by two-way ANOVA; the effect of diet was significant for adiponectin $(P<0.001)$, the effect of EPA was significant for adiponectin/WAT $(P<0.05)$ and the effect of diet was marginally significant for adiponectin/WAT $(P=0.07)$. CEPA, control EPA; OEPA, overweight EPA.

of all fat depots but only in control animals. Hill et al. (1993) observed a decrease in all fat depots of adult male Wistar rats after 6 months of treatment with dietary $n-3$ PUFA, suggesting that the potential anti-adipogenic actions of $n$-3 PUFA are dependent on treatment duration and metabolic status. In this sense, if our EPA treatment lasted more than 5 weeks, it could be possible to observe a significant decrease in the weight of all fat depots and not only in the retroperitoneal fat pad. Paradoxically, the lowering effects of EPA on adiposity contrast with the lack of effects on bodyweight gain observed in control rats. Previous studies have 
(A)

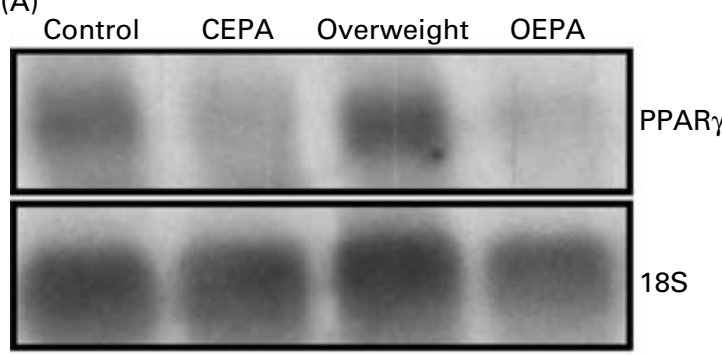

(C) Control

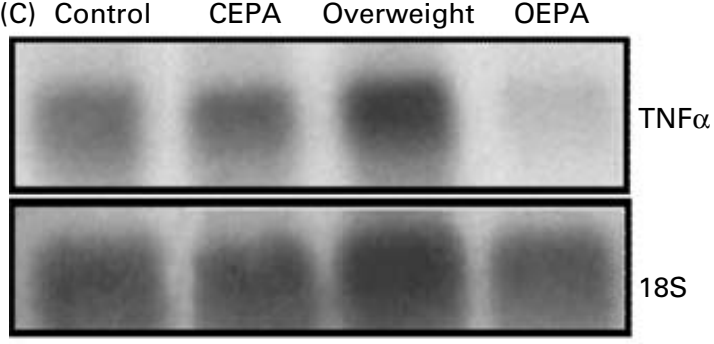

(B)
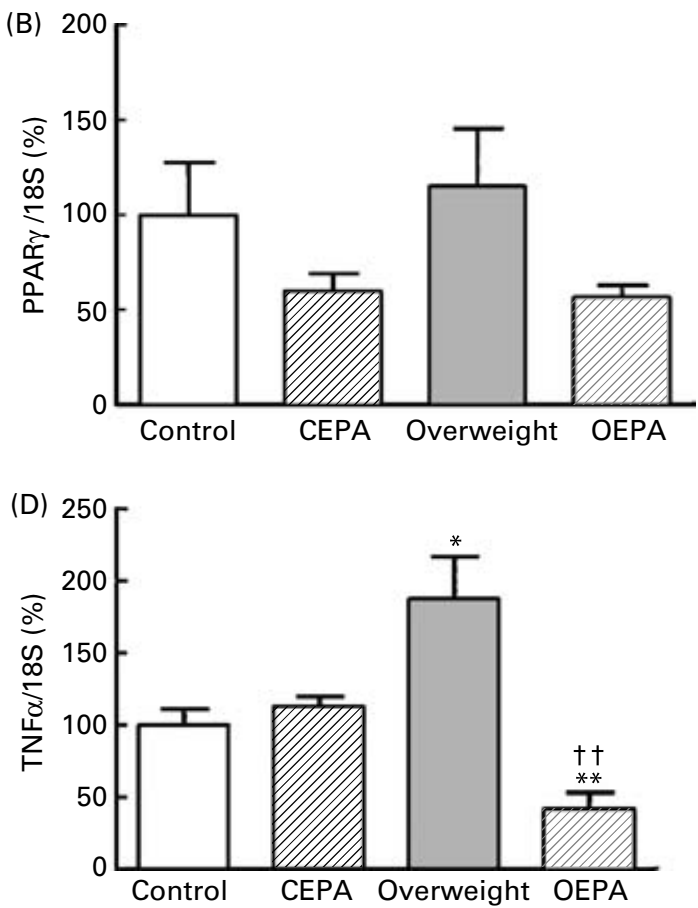

Fig. 6. Effects of EPA on PPAR $\gamma$ mRNA (A and B) and TNF $\alpha$ mRNA (C and D) expression in epididymal fat in control and overweight-cafeteria rats. The expression level of $18 \mathrm{~S}$ ribosomal RNA was determined and used as an internal control to correct for minor variation in total RNA amount. Densitometric scanning was used to determine the relative amount of PPAR $\gamma, T N F \alpha$ mRNA and 18S RNA. Data are means for at least four independent animals per group, with standard errors represented by vertical bars. Statistical analysis was by two-way ANOVA; the effect of EPA was significant for PPAR $\gamma$ mRNA $(P<0 \cdot 001)$ and the diet $\times$ EPA interaction was significant for TNF $\alpha$ mRNA $(P<0.001)$. When an interaction was found, comparisons between groups were analysed by a Student's $t$ test. Mean value was significantly different from that of the control group: ${ }^{\star} P<0.05,{ }^{\star \star} P<0.01$. $\dagger \dagger$ Mean value was significantly different from that of the overweight group $(P<0 \cdot 01)$. CEPA, control EPA; OEPA, overweight EPA.

found that a fish oil-enriched diet induces greater gain in lean body mass and a lower gain in fat in comparison with animals fed with other type of enriched diets ( $\mathrm{Su} \&$ Jones, 1993). Although we have not performed any body composition measurements, our data also suggest that EPA treatment could induce a body composition redistribution, which could explain that a reduction in adipose tissue weight did not always mean a decrease in total body weight, as observed in the present study.

An increase of lipolysis could be a potential mechanism responsible for the limitation of retroperitoneal fat weight after EPA treatment. The increase in fat pad weights in high-fat-fed animals was accompanied by a decrease in the isoproterenol-induced lipolytic response, as previously shown (Portillo et al. 1999). The present study demonstrated a lack of effect of EPA on both basal and isoproterenol-stimulated lipolysis, suggesting that the potential anti-adipogenic properties of this fatty acid are not mediated by a lipolytic action in WAT. In addition, our in vitro study in cultured adipocytes also argues against a direct lipolytic action of this fatty acid (Perez-Matute et al. 2005).

PPAR $\gamma$, a member of the nuclear hormone receptor superfamily, is an important adipogenic transcription factor. Several articles have described an increase in the expression of this factor in WAT of high-fat-fed obese animals (Margareto et al. 2002; Lopez et al. 2003). In the present study, we have also observed a slight non-significant increase in the expression of this factor after the cafeteria-diet consumption without statistical significance. Several studies have reported the ability of EPA to modulate the expression and activity of this adipogenic factor, although the results are controversial. Thus, some studies have observed an inhibitory action of EPA on PPARy (Reseland et al. 2001) while others have observed an stimulatory effect (Chambrier et al. 2002). Our data revealed that EPA-treated animals exhibited a decrease in the adipogenic PPAR $\gamma$ gene expression levels, which could impair the adipogenic process, contributing to the decrease in WAT weight observed in these animals.

Targeting apoptotic pathways in adipocytes has been proposed as a potential novel treatment for obesity (NelsonDooley et al. 2005). We tested if an increase in apoptosis could be contributing to the reduced WAT size. Ruzickova et al. (2004) demonstrated that $n-3$ PUFA limit diet-induced obesity in mice by reducing cellularity of adipose tissue and, although they did not directly measure apoptosis, their data suggest a potential apoptotic action of EPA. Our data showed for the first time that an increase in apoptosis is involved in the more efficient action of EPA on the reduction of WAT size observed in control rats. Thus, the rise in the apoptotic cell death rate would decrease adipocyte number and consequently adipose tissue weight. Finally, we also observed in the present study that the cafeteria diet strongly impaired this apoptotic action induced by EPA, suggesting that EPA-induced apoptosis depends on the nutritional and metabolic status of animals. Furthermore, the opposite effects of EPA observed in control and cafeteria-fed rats could be also 
due to the different percentage of EPA in relation to total lipids supplied by both types of diets. In the present study, the EPA supplemented by oral administration in rats fed with the cafeteria diet (62\% of energy as fat) accounts for $2.1 \%$ of the total lipids. However, EPA accounts for a $30.2 \%$ of the total lipids ingested by the rats fed with the control diet (6\% of energy as fat) and orally treated with EPA. In this context, recent evidence suggests that the ratio between different types of fatty acids such as the $n-6$ and $n-3$ fatty acids is an important fact in determining their effects on health (Simopoulos, 2002; Weiss et al. 2005).

Several studies have suggested that obesity could be an inflammatory disease (Das, 2001; Ramos et al. 2003). In this context, several markers of chronic inflammation, such as $\mathrm{TNF} \alpha$, have been found to be associated with obesity and insulin resistance (Ramos et al. 2003). In fact, similarly to our present data, an induction of TNF $\alpha$ mRNA expression and activity was observed in adipose tissue from different rodent models of obesity (Hotamisligil et al. 1993; Morin et al. 1997). Here, we have demonstrated for the first time that EPA treatment was able to down regulate the increased adipose $\mathrm{TNF} \alpha$ gene expression induced by a high-fat diet. Although the mechanisms involved in this inhibitory action have not been yet elucidated, it has been suggested that EPA could prevent the NF- $\kappa \mathrm{B}$ activation (Zhao et al. 2004). The inflammatory state associated with obesity seems to be predominantly initiated and to reside in adipose tissue, although other metabolically key organs may also be involved during the course of the disease (Wellen \& Hotamisligil, 2003). In addition, this inflammatory state associated with obesity has been proposed to be the link with several obesity-associated disorders such as insulin resistance (Dandona et al. 2004). Indeed, increased TNF $\alpha$ levels have been associated with increased insulin resistance in adipose tissue, by reducing the phosphorylation of insulin receptor sustrate-1 (Hotamisligil, 1999). Therefore, our data lead us to suggest that the improvement in insulin sensitivity induced by EPA could be mediated, at least in part, by decreasing the inflammation in the adipose tissue of the overweight rats.

Adiponectin is an anti-inflammatory adipokine with an important role in insulin sensitivity (Combs et al. 2004). Thus, hypoadiponectinaemia has been related to the development of insulin resistance and cardiovascular risk associated with obesity (Hotta et al. 2001; Kubota et al. 2002; Kumada et al. 2003). However, our data showed that levels of circulating adiponectin were increased in overweight rats fed with the high-fat diet. Several studies have also shown an increase in both adiponectin circulating levels and gene expression in early stages of obesity $(11,15$ and $21 \mathrm{~d}$ of high-fat-diet consumption) (Li et al. 2002; Lopez et al. 2004; Perez-Echarri et al. 2005) suggesting that this could be an initial mechanism in the adaptation to high energy intake. In the present study, when the levels of circulating adiponectin were corrected for adiposity, a moderate non-significant decrease was observed in the untreated cafeteria rats, accompanied by a decrease in the expression of this adipokine, suggesting an impairment in adiponectin production processes by the overweight adipocytes. These results suggest that when obesity is more established (for example, after $65 \mathrm{~d}$ of a high-fat diet as described by Lopez et al. (2005)) the ability of adipocytes to express and secrete adiponectin is more strongly impaired. Our data also suggest that this ability of adipocytes to produce adiponectin was significantly increased by the administration of EPA, which could contribute to the insulin-sensitising properties of this fatty acid. Furthermore, a negative relationship was found in the present study between adiposity-corrected adiponectin plasma levels and the HOMA index which supports the beneficial effects of EPA supplementation on insulin sensitivity. A recently published study (Flachs et al. 2006) has also observed that feeding mice with a high-fat diet enriched with EPA and DHA leads to elevated systemic concentrations of adiponectin, and suggested that this increase could explain, to some extent, the $n-3$ EPA antidiabetic properties.

In summary, our data suggest that EPA supplementation could help to reduce adiposity through the down regulation of PPAR $\gamma$ and through the increase of apoptosis in WAT. EPA also exhibited antidiabetic properties which could be related to its reducing effects on the pro-inflammatory cytokine $\mathrm{TNF} \alpha \mathrm{mRNA}$ levels in adipose tissue and increasing the capacity of the adipose tissue to produce the insulin-sensitising adipokine, adiponectin. In addition, the present study suggests that some EPA actions seem to be dependent on diet composition and the physiological and metabolic status of animals, which could be important to take into account when considering supplementation with $n$-3-enriched-products.

\section{Acknowledgements}

The present study has been supported in part by the Government of Navarra (Department of Education and Culture) and Línea Especial de Investigación 'Nutrición, Salud y Obesidad' (University of Navarra). P. P.-M. was supported by a doctoral grant from the Danone Institute (Spain) and the Asociación de Amigos de la Universidad de Navarra (Spain). The expert technical assistance of Ana Lorente and Veronica Ciaurriz is gratefully acknowledged. EPA was kindly provided by Brudy S.L (Spain).

\section{References}

Berraondo B, Marti A, Duncan JS, Trayhurn P \& Martinez JA (2000) Up-regulation of muscle UCP2 gene expression by a new $\beta 3$-adrenoceptor agonist, trecadrine, in obese (cafeteria) rodents, but downregulation in lean animals. Int J Obes Relat Metab Disord 24, $156-163$.

Browning LM (2003) $n$-3 Polyunsaturated fatty acids, inflammation and obesity-related disease. Proc Nutr Soc 62, 447-453.

Calder PC (2001) Omega 3 polyunsaturated fatty acids, inflammation and immunity. World Rev Nutr Diet 88, 109-116.

Campion J \& Martinez JA (2004) Ketoconazole, an antifungal agent, protects against adiposity induced by a cafeteria diet. Horm Metab Res 36, 485-491.

Chambrier C, Bastard JP, Rieusset J, Chevillotte E, Bonnefont-Rousselot D, Therond P, Hainque B, Riou JP, Laville M \& Vidal H (2002) Eicosapentaenoic acid induces mRNA expression of peroxisome proliferator-activated receptor $\gamma$. Obes Res 10, 518-525.

Combs TP, Pajvani UB, Berg AH, et al. (2004) A transgenic mouse with a deletion in the collagenous domain of adiponectin displays elevated circulating adiponectin and improved insulin sensitivity. Endocrinology 145, 367-383. 
Connor WE (2000) Importance of $n$-3 fatty acids in health and disease. Am J Clin Nutr 71, 171S-175S.

Dandona P, Aljada A \& Bandyopadhyay A (2004) Inflammation: the link between insulin resistance, obesity and diabetes. Trends Immunol 25, 4-7.

Das UN (2001) Is obesity an inflammatory condition? Nutrition 17, 953-966.

Flachs P, Mohamed-Ali V, Horakova O, Rossmeisl M, HosseinzadehAttar MJ, Hensler M, Ruzickova J \& Kopecky J (2006) Polyunsaturated fatty acids of marine origin induce adiponectin in mice fed a high-fat diet. Diabetologia 49, 1-4.

Havel PJ (2004) Update on adipocyte hormones: regulation of energy balance and carbohydrate/lipid metabolism. Diabetes 53, Suppl. 1, S143-S151.

Hill JO, Peters JC, Lin D, Yakubu F, Greene H \& Swift L (1993) Lipid accumulation and body fat distribution is influenced by type of dietary fat fed to rats. Int J Obes Relat Metab Disord 17, 223-236.

Hotamisligil GS (1999) The role of TNF $\alpha$ and TNF receptors in obesity and insulin resistance. J Intern Med 245, 621-625.

Hotamisligil GS, Shargill NS \& Spiegelman BM (1993) Adipose expression of tumor necrosis factor- $\alpha$ : direct role in obesitylinked insulin resistance. Science 259, 87-91.

Hotta K, Funahashi T, Bodkin NL, Ortmeyer HK, Arita Y, Hansen BC \& Matsuzawa Y (2001) Circulating concentrations of the adipocyte protein adiponectin are decreased in parallel with reduced insulin sensitivity during the progression to type 2 diabetes in rhesus monkeys. Diabetes 50, 1126-1133.

Hu E, Liang P \& Spiegelman BM (1996) AdipoQ is a novel adiposespecific gene dysregulated in obesity. J Biol Chem 271, 10697-10703.

Kawaguchi K, Sugiyama T, Hibasami H \& Toyoda N (2003) PPAR- $\gamma$, TNF- $\alpha$ messenger RNA levels and lipase activity in the pregnant and lactating rat. Life Sci 72, 1655-1663.

Kubota N, Terauchi Y, Yamauchi T, et al. (2002) Disruption of adiponectin causes insulin resistance and neointimal formation. $J$ Biol Chem 277, 25863-25866.

Kumada M, Kihara S, Sumitsuji S, et al. (2003) Association of hypoadiponectinemia with coronary artery disease in men. Arterioscler Thromb Vasc Biol 23, 85-89.

Kusunoki M, Tsutsumi K, Hara T, et al. (2003) Ethyl icosapentate (omega-3 fatty acid) causes accumulation of lipids in skeletal muscle but suppresses insulin resistance in OLETF rats. Otsuka Long-Evans Tokushima Fatty. Metabolism 52, 30-34.

Li J, Yu X, Pan W \& Unger RH (2002) Gene expression profile of rat adipose tissue at the onset of high-fat-diet obesity. Am J Physiol 282, E1334-E1341.

Lopez IP, Marti A, Milagro FI, Zulet Md Mde L, Moreno-Aliaga MJ, Martinez JA \& De Miguel C (2003) DNA microarray analysis of genes differentially expressed in diet-induced (cafeteria) obese rats. Obes Res 11, 188-194.

Lopez IP, Milagro FI, Marti A, Moreno-Aliaga MJ, Martinez JA \& De Miguel C (2004) Gene expression changes in rat white adipose tissue after a high-fat diet determined by differential display. Biochem Biophys Res Commun 318, 234-239.

Lopez IP, Milagro FI, Marti A, Moreno-Aliaga MJ, Martinez JA \& De Miguel C (2005) High-fat feeding period affects gene expression in rat white adipose tissue. Mol Cell Biochem 275, 109-115.

Margareto J, Aguado M, Oses-Prieto JA, Rivero I, Monge A, Aldana I, Marti A \& Martinez JA (2000) A new NPY-antagonist strongly stimulates apoptosis and lipolysis on white adipocytes in an obesity model. Life Sci 68, 99-107.

Margareto J, Gomez-Ambrosi J, Marti A \& Martinez JA (2001) Time-dependent effects of a high-energy-yielding diet on the regulation of specific white adipose tissue genes. Biochem Biophys Res Commun 283, 6-11.

Margareto J, Rivero I, Monge A, Aldana I, Marti A \& Martinez JA (2002) Changes in UCP2, PPAR $\gamma 2$, and $\mathrm{c} / \mathrm{EBP} \alpha$ gene expression induced by a neuropeptide Y (NPY) related receptor antagonist in overweight rats. Nutr Neurosci 5, 13-17.

Marti A \& Martinez JA (1999) Leptin and body weight regulation (article in Spanish). An Sist Sanit Navar 22, 353-363.

Moreno-Aliaga MJ, Campion J, Milagro FI, Berjón A \& Martínez JA (2005) Adiposity and proinflammatory state: the chicken or the egg. Adipocytes 1, 1-16.

Moreno-Aliaga MJ, Lamas O, Marti A \& Martinez JA (2002) Effects of a $\beta 3$-adrenergic agonist on glucose uptake and leptin expression and secretion in cultured adipocytes from lean and overweight (cafeteria) rats. Biochem Biophys Res Commun 291, 1201-1207.

Mori TA \& Beilin LJ (2004) Omega-3 fatty acids and inflammation. Curr Atheroscler Rep 6, 461-467.

Mori Y, Murakawa Y, Katoh S, Hata S, Yokoyama J, Tajima N, Ikeda Y, Nobukata H, Ishikawa T \& Shibutani Y (1997) Influence of highly purified eicosapentaenoic acid ethyl ester on insulin resistance in the Otsuka Long-Evans Tokushima Fatty rat, a model of spontaneous non-insulin-dependent diabetes mellitus. Metabolism 46, 1458-1464.

Mori Y, Murakawa Y, Yokoyama J, Tajima N, Ikeda Y, Nobukata H, Ishikawa T \& Shibutani Y (1999) Effect of highly purified eicosapentaenoic acid ethyl ester on insulin resistance and hypertension in Dahl salt-sensitive rats. Metabolism 48, 1089-1095.

Morin CL, Eckel RH, Marcel T \& Pagliassotti MJ (1997) High fat diets elevate adipose tissue-derived tumor necrosis factor- $\alpha$ activity. Endocrinology 138, 4665-4671.

Murata M, Kaji H, Takahashi Y, Iida K, Mizuno I, Okimura Y, Abe H \& Chihara K (2000) Stimulation by eicosapentaenoic acids of leptin mRNA expression and its secretion in mouse 3T3-L1 adipocytes in vitro. Biochem Biophys Res Commun 270, 343-348.

Nelson-Dooley C, Della-Fera MA, Hamrick M \& Baile CA (2005) Novel treatments for obesity and osteoporosis: targeting apoptotic pathways in adipocytes. Curr Med Chem 12, 2215-2225.

Nobukata H, Ishikawa T, Obata M \& Shibutani Y (2000) Long-term administration of highly purified eicosapentaenoic acid ethyl ester prevents diabetes and abnormalities of blood coagulation in male WBN/Kob rats. Metabolism 49, 912-919.

Parrish CC, Pathy DA \& Angel A (1990) Dietary fish oils limit adipose tissue hypertrophy in rats. Metabolism 39, 217-219.

Perez-Echarri N, Perez-Matute P, Martinez JA, Marti A \& MorenoAliaga MJ (2005) Serum and gene expression levels of leptin and adiponectin in rats susceptible or resistant to diet-induced obesity. J Physiol Biochem 61, 333-342.

Perez-Matute P, Marti A, Martinez JA, Fernandez-Otero MP, Stanhope KL, Havel PJ \& Moreno-Aliaga MJ (2005) Eicosapentaenoic fatty acid (EPA) increases leptin secretion from primary cultured rat adipocytes: role of glucose metabolism. Am J Physiol $\mathbf{2 8 8}$ R1682-R1688.

Perez-Matute P, Marti A, Martinez JA \& Moreno-Aliaga MJ (2003) Effects of arachidonic acid on leptin secretion and expression in primary cultured rat adipocytes. $J$ Physiol Biochem 59, 201-208.

Peyron-Caso E, Taverna M, Guerre-Millo M, Veronese A, Pacher N, Slama G \& Rizkalla SW (2002) Dietary (n-3) polyunsaturated fatty acids up-regulate plasma leptin in insulin-resistant rats. J Nutr 132, 2235-2240.

Portillo MP, Simon E, Garcia-Calonge MA \& Del Barrio AS (1999) Effect of high-fat diet on lypolisis in isolated adipocytes from visceral and subcutaneous WAT. Eur J Nutr 38, 177-182.

Raclot T, Groscolas R, Langin D \& Ferre P (1997) Site-specific regulation of gene expression by $\mathrm{n}-3$ polyunsaturated fatty acids in rat white adipose tissues. J Lipid Res 38, 1963-1972.

Ramos EJ, Xu Y, Romanova I, Middleton F, Chen C, Quinn R, Inui A, Das U \& Meguid MM (2003) Is obesity an inflammatory disease? Surgery 134, 329-335.

Reseland JE, Haugen F, Hollung K, Solvoll K, Halvorsen B, Brude IR, Nenseter MS, Christiansen EN \& Drevon CA (2001) Reduction 
of leptin gene expression by dietary polyunsaturated fatty acids. $J$ Lipid Res 42, 743-750.

Rustan AC, Hustvedt BE \& Drevon CA (1993) Dietary supplementation of very long-chain n-3 fatty acids decreases whole body lipid utilization in the rat. J Lipid Res 34, 1299-1309.

Ruxton C (2004) Health benefits of omega-3 fatty acids. Nurs Stand 18, $38-42$.

Ruzickova J, Rossmeisl M, Prazak T, Flachs P, Sponarova J, Veck M, Tvrzicka E, Bryhn M \& Kopecky J (2004) Omega-3 PUFA of marine origin limit diet-induced obesity in mice by reducing cellularity of adipose tissue. Lipids 39, 1177-1185.

Simopoulos AP (2002) The importance of the ratio of omega-6/ omega-3 essential fatty acids. Biomed Pharmecother 56, $365-379$.

Stefan N, Bunt JC, Salbe AD, Funahashi T, Matsuzawa Y \& Tataranni PA (2002) Plasma adiponectin concentrations in children: relationships with obesity and insulinemia. J Clin Endocrinol Metab 87, 4652-4656.

Su W \& Jones PJ (1993) Dietary fatty acid composition influences energy accretion in rats. J Nutr 123, 2109-2114.

Trayhurn P \& Wood IS (2005) Signalling role of adipose tissue: adipokines and inflammation in obesity. Biochem Soc Trans 33, 1078-1081.

Weiss LA, Barrett-Connor E \& Von Muhlen D (2005) Ratio of $n-6$ to $n-3$ fatty acids and bone mineral density in older adults: the Rancho Bernardo Study. Am J Clin Nutr 81, 934-938.

Wellen KE \& Hotamisligil GS (2003) Obesity-induced inflammatory changes in adipose tissue. J Clin Invest 112, $1785-1788$

Zhao Y, Joshi-Barve S, Barve S \& Chen LH (2004) Eicosapentaenoic acid prevents LPS-induced TNF- $\alpha$ expression by preventing NFкB activation. J Am Coll Nutr 23, 71-78. 